\title{
Gender roles and the expression of driving anger amongst Ukrainian drivers
}

\author{
M.J.M. Sullman", A.N. Stephens ${ }^{*}$ and T. Zaporozhets ${ }^{\mathfrak{f}}$ \\ \# Driving Research Group, Cranfield University, Bedfordshire, UK \\ * Accident Research Centre, Monash University, Clayton, Australia \\ Corresponding author \\ ${ }^{£}$ National Aviation University, Kiev, Ukraine \\ zaporozhets.tanya@gmail.com
}




\section{Abstract}

The current study investigated the validity of the revised (25-item) version of the Driving Anger Expression Inventory (DAX) on a novel sample of 385 drivers from Ukraine. The role of sex and gender-roles in relation to self-reported aggressive tendencies were also examined. Confirmatory Factor Analysis supported the four-factor structure of the DAX (Adaptive/Constructive Expression; Use of the Vehicle to Express Anger; Verbal Aggressive Expression and Personal Physical Aggressive Expression) and the three aggressive factors were found to have positive relationships with trait anger and driving anger, while adaptive/constructive expression was negatively related to trait and driving anger. Drivers who reported recent near misses or loss of concentration scored higher on verbal aggressive expression. Those who had recently received a traffic ticket also reported higher levels of all three types of aggressive anger expression. Further, the presence of feminine traits, but not sex, predicted more adaptive/constructive behaviours and lower scores for verbal aggressive expression, personal physical aggressive expression and total aggressive expression. However, masculine traits did not predict any of these factors. This research concludes that the revised DAX is a valid tool to measure the expression of driving anger and that the endorsement of feminine traits is related to less aggressive expression of driving anger.

Keywords: Driving anger; Aggressive driving; Anger; Anger expression; Ukraine, genderrole 


\section{Introduction}

Ukraine has one of the highest road fatality rates in Europe. Although the country has around 45.5 million inhabitants the number of people killed on the road in 2010 (6116 fatalities) dwarfs the number killed in the similarly populous Spain (2478), along with much more populated European countries, such as the UK (1905), Germany (3648), France (3992) and even Italy (4237). ${ }^{(1)}$ The fatality rate in Ukraine is $13.5 / 100,000$ people, which compares very poorly to the European road safety leaders the UK $(3.7 / 100,000)$, Sweden $(3.0 / 100,000)$ and the Netherlands $(3.9 / 100,000) .{ }^{(1)}$ Motor vehicle crashes not only end, or irreversibly alter, many lives they also have a substantial social and financial cost. According to the Ukraine Ministry of Internal Affairs, the economy annually loses at least 3\% of GDP because of motor vehicle collisions.

Although the crash statistics for Ukraine compare very unfavourably to those from other European countries and the cost to the Ukrainian economy is high, searches on "ScienceDirect" and "PsychInfo" did not find a single journal article that focused on road safety in Ukraine. Although this does not mean that no road-safety related research is being conducted in the country, it is interesting to note this absence.

A growing body of research suggests anger plays a substantial role in risky and aggressive driving and is thus a substantial contributor to motor vehicle collisions. ${ }^{(2-8)}$ Previous research has also noted that angry drivers: take longer to respond to hazards, ${ }^{(9,10)}$ follow lead vehicles more closely, ${ }^{(11)}$ have worse vehicle control, ${ }^{(12,13)}$ cross more yellow/red traffic lights and drive faster. ${ }^{(14-17)}$ It is therefore no surprise that some researchers have described driving anger as one of the most important predictors of aggressive and risky driving behaviour. ${ }^{(18)}$ Several self-report studies confirm this by highlighting the relationships between anger tendencies, aggressive expressions and crash related conditions, including near misses ${ }^{(19)}$ and crashes. ${ }^{(20-25)}$

The majority of research on the expression of driving anger has used the Driving Anger Expression Inventory (DAX). ${ }^{(26)}$ The most frequently used version of the DAX contains 49items and four factors, which are: Verbal Aggressive Expression (VAE) - verbally expressing anger (e.g. swearing at the other driver); Personal Physical Aggressive Expression (PPAE) (e.g. make hostile gestures); Use of the Vehicle to Express Anger (UoV) (e.g. drive a little faster); and Adaptive/Constructive Expression (A/C) - constructive behaviours that a driver can engage in (e.g. concentrate on their own driving). Finally an overall measure of aggressive expression (Total Aggressive Expression) can be calculated by summing the 
scores of VAE, PPAE and UoV. These four factors and Total Aggressive Expression have been found to have good internal reliability $(\alpha=0.80-0.90) .{ }^{(26)}$

The DAX has been used to study the expression of driving anger amongst drivers from: New Zealand, ${ }^{(23)}$ France, ${ }^{(27)}$ Malaysia, ${ }^{(28)}$ Romania, ${ }^{(29)}$ Serbia, ${ }^{(30)}$ Spain, ${ }^{(31)}$ Turkey, ${ }^{(32)}$ the USA, ${ }^{(26)}$ along with the UK and Republic of Ireland. ${ }^{(24)}$ The vast majority of these studies have supported the four factor structure of the DAX, except for Herrero-Fernandez, ${ }^{(31)}$ who included an additional four items from an extra subscale (displaced anger) and thus found a five factor solution. However, of greater concern were the findings of Sullman ${ }^{(23)}$ and Villeux and Delhomme, ${ }^{(27)}$ neither of whom found support for the PPAE factor. This may be due to the extremely low level at which drivers from New Zealand and France reported personal physical aggressive expression.

While the DAX has been validated across a variety of countries and driving populations there has been some degree of variability regarding the relationships the DAX factors have with demographic and descriptive characteristics. Several researchers have found that females report more adaptive/constructive means of dealing with anger, ${ }^{(30,32)}$ while others have found no sex differences on this factor. ${ }^{24,27)}$ Some research has found that males tend to engage more often in personal physical aggressive expression, ${ }^{(18,32)}$ while others have found no sex differences on this factor. ${ }^{(33,34)}$ Therefore, it is unclear whether this represents underlying differences in driving populations, sampling techniques or is an artefact of the differing factor structures used.

While not directly tested using the DAX, gender roles have also been found to predict aggression while driving. ${ }^{(35)}$ These researchers suggest that it is not sex that influences the likelihood of aggression but the gender-role endorsed by the driver. The Bem Sex-Role Inventory (36) was designed to measure the gender attributes adopted by a person. For example, the extent to which "male" characteristics and "female" characteristics are endorsed by the individual. Traditionally aggression and assertiveness are perceived as masculine traits. ${ }^{(37)}$ Therefore, it may not be that males are more aggressive drivers, but that drivers who adopt more masculine traits are more likely to exhibit aggression while driving. Ozkan and Lajunen ${ }^{(35)}$ found that masculinity was related to risky and aggressive driving. They argue that gender role might be just as important as sex in predicting aggressive driving. The research therefore suggests that gender roles may create a social boundary of "appropriate behaviour" that has been relatively unexplored in the driving context. This may, at least in part, explain the 
inconsistency regarding the sex effect on aggressive driving. Therefore, one aim of the present study is to explore the effect of gender roles in the expression of driving anger in a sample of Ukrainian drivers.

As might be expected, age has consistently been found to be related to the expression of driving anger. For example, research has found a significant negative relationship between age and total aggressive expression (e.g., ${ }^{24,25,30}$ ). Age has also been found to be negatively related to personal physical aggressive expression, use of a vehicle and verbal aggressive expression, while adaptive/constructive expression has been found to be positively related to age. ${ }^{(38)}$ Verbal aggressive expression has also been found to be negatively related to age amongst Turkish taxi drivers and private vehicle drivers from the UK and Republic of Ireland ${ }^{(25,33)}$.In fact, aside from Moore and Dahlen ${ }^{(39)}$ all previous research has found some relationships between age and the DAX subscales. ${ }^{(24,27,31,32)}$

Although all of the previous studies using the DAX have investigated the effects of driver demographics on the expression of driving anger, less attention has been given to the relationships between DAX scores and personality variables. One potential reason for this is the size of the original DAX, which had 49-items, which resulted in a long questionnaire if one or more personality variables were also included. However, recent research has refined the DAX using a sample from the British Isles (the UK and Republic of Ireland) to produce a 25 -item version of the scale. The present study aimed to validate the shortened version of the DAX using a novel sample of Ukrainian drivers. Discriminant validity was investigated by testing the relationships the DAX factors had with crashes and crash-related conditions. Convergent validity was investigated by measuring the relationships the DAX factors had with driving anger (Driving Anger Scale - DAS), general trait anger (Trait Anger Scale TAS) and road rage behaviours. A further aim was to investigate the relationships the DAX factors have with the demographic and descriptive variables, such as age and sex.

\section{Method}

\subsection{Participants}

A total of 385 drivers from Ukraine (males $=63.6 \%$ ) completed the online questionnaire. Participants were recruited from the National Aviation University via email or responded to a forum for Ukrainian motorists. Participants had an average age of 33.74 years $(S D=9.41$; 
range 18 to 76 ), had held a driving licence for 9.23 years $(S D=9.58$, range 1 month to 46 ) and had an annual mileage of approximately 9,480 kilometres $(S D=7,824)$ (Table 1$)$.

\subsection{Materials}

Aggressive expression of anger: The 25-item four-factor revised DAX was used to measure how drivers express their anger whilst driving. ${ }^{(24)}$ The revised DAX is an abridged version of the original 49-item Driving Anger Expression Inventory, ${ }^{(26)}$ which retains the original fourfactors: Adaptive/Constructive expression; Use of the Vehicle to express anger; Verbal Aggressive Expression and Personal Physical Aggressive Expression. For each of the 25items, respondents were asked to rate, on a four-point scale $(1=$ Almost never to $4=$ Almost always), the frequency of each potential reaction to feeling angry while driving. Higher scores for each item represent stronger tendencies for each of the four types of responses. The 25item DAX has shown good reliability with Cronbach's $\alpha$ ranging from 0.74 to 0.88 for the four subscales. ${ }^{(24)}$ Convergent validity has also been shown through strong positive correlations between total aggressive expression scores and self-reported acts of aggression. (24)

Trait Driving Anger: The 14-item Driving Anger Scale (DAS) was used to measure traitdriving anger. ${ }^{(20)}$ The DAS and the original form DAX have moderate correlations ${ }^{(26)}$ and thus the DAS was used to investigate the convergent validity of the short version of the DAX. Participants report the level of anger elicited by each of the 14 potentially anger inducing situations on a five-point scale $(1=$ not at all to $5=$ very much $)$. Scores for each item are summed to produce a final DAS score, with higher scores representing stronger tendencies to experience anger while driving. The DAS short-form has demonstrated good internal consistency $(\alpha=0.80) .{ }^{(20)}$ The validity of the DAS has also been shown through correlations with Spielberger's ${ }^{(40)}$ Trait Anger Scale. ${ }^{(20,41)}$

General Trait Anger: The 10-item Trait Anger Scale (TAS) was used as a measure of general trait anger ${ }^{(40,42)}$ to further investigate the convergent validity of the DAX. The TAS has been found to be positively correlated with the aggressive forms of anger expression and to negatively correlate with the adaptive/constructive factor. Participants were presented with 10 statements and asked to indicate how applicable to them each was on a 4-point scale $(1=$ Almost never to $4=$ Almost always). The TAS exhibits good reliability with Cronbach $\alpha$ ranging from 0.81 to $0.91{ }^{(40,42)}$ 
Crash related conditions: The questionnaire also included six items from the Driving Survey (26). These measured how many times in the last three months drivers had: been fined or prosecuted for a driving offence (excluding parking tickets), lost concentration, lost control of their vehicle, experienced a near-miss, had a minor crash or a major crash. These were used as a measure of discriminant validity, as previous research has shown positive relationships between scores on the DAX and crash-related conditions. $(25,26,28)$

Gender roles: The short version of the Bem Sex-Role Inventory (BSRI) ${ }^{(36)}$ was used to assess masculinity and femininity. The short version contains 20 statements designed to be either masculine (10 items) or feminine (10 items) (i.e., I am assertive; I am sensitive). For each item, participants responded on a 7-point scale as to how true each statement is about them (1 $=$ Never or almost never true; $7=$ Almost always true). The BSRI short has good validity and reliability, with Cronbach $\alpha$ ranging from 0.75 to $0.90 .{ }^{(36)}$ Despite the age of the scale, the BSRI is still widely used as a measure of gender-roles (e.g., see ${ }^{43}$ ).

Demographics and general speed preferences: Participants were also asked to report their sex, age and preferred speed across five types of roadways (actual speed limit in brackets): motorway $(130 \mathrm{~km} / \mathrm{h})$; busy main street $(50 \mathrm{~km} / \mathrm{h})$; residential zones $(60 \mathrm{~km} / \mathrm{h})$; pedestrian zones $(20 \mathrm{~km} / \mathrm{h})$; regional roads $(100 \mathrm{~km} / \mathrm{h})$. Participants also provided information regarding their licence tenure and annual mileage.

\subsection{Procedure}

Firstly, the questionnaire was translated into Ukrainian by a professional translator and checked for consistency by one of the authors who is fluent in both languages. The questionnaire was then hosted by Qualtrics and a link to the online questionnaire was distributed via email to potential participants and posted on a forum for Ukrainian motorists. The questionnaire did not ask whether the participants had received the invitation to participate via email or on the forum. In order to participate, drivers had to hold a valid licence to drive in Ukraine and had driven at least once in the last six months. Drivers were informed that the study was voluntary, that their responses were anonymous and they received no reward for participation. The study was approved by the University ethics committee.

\subsection{Data handling}

There were no missing data for the scale responses, but there were a few occasions where preferred speed responses were provided as a range rather than an absolute number. In these 
cases the mid-point in the range was taken as the response. The crash variables produced very few affirmative responses. For example, only three of the participants had been involved in a major crash in the past three months. Therefore, minor and major crashes were combined into one variable. Six data points were missing for the loss of concentration variable and this is reflected in the altered degrees of freedom.

Prior to analysis, the distribution of each variable was checked for normality. The BSRI, TAS, DAS_short and the four-factors from the 25-item DAX Adaptive / Constructive expression, verbal aggressive expression and use of the vehicle to express anger were within normal range (Skewness <1; Kurtosis <1). However, personal physical aggressive expression and total aggressive expression (TAE) were positively skewed and these variables were analysed using non-parametric tests. For comparisons between males and females, Cohen's d effect sizes were used. The traditional interpretation of <.10 small; <.30 medium and >.50 large ${ }^{(45)}$ were used.

\section{Results}

\subsection{Descriptive Variables}

Table 1 shows the driver demographics by sex as well as the mean responses regarding preferred driving speeds. As can be seen in Table 1, males and females did not differ according to age and licence tenure. However, males reported a higher annual mileage than females and also preferred driving at faster speeds than females in residential areas, on the motorway and on regional roads.

\section{[insert Table 1 about here]}

\subsection{Driving Anger Expression in Ukraine}

Table 2 shows the means and standard deviations of the DAX items. The most commonly reported items were from the Adaptive/Constructive factor, showing that drivers in Ukraine tend to incorporate strategies to resolve or reduce anger rather than react aggressively. For example, the most commonly reported behaviours were paying attention to others' driving to avoid accidents, choosing not to reciprocate aggressive behaviours or to "stoop to their level", paying attention to being a safer driver and thinking of positive behaviours to cope with the situation. The three least commonly reported responses were from the personal physical aggressive expression factor. These were: trying to get out of the car to tell the other driver off or engage in a physical fight, and bumping the other driver's vehicle with their own. The low 
scores on the personal physical aggressive expression factor explain why this factor was positively skewed.

\section{[insert Table 2 about here]}

Overall, drivers reported relatively low aggressive responses to anger, scoring an average of $1.64(S D=.49)$ out of a possible 4 . Adaptive/constructive expressions were the most commonly reported, followed by verbal aggressive expression and then use of the vehicle to express anger. Personal physical aggressive expression was the least commonly reported. The order of the factors, by subscale mean, was the same as previous research using the 49-item version of the $\operatorname{DAX}{ }^{(25,27,28)}$ and also the research that developed the 25-item DAX. ${ }^{(24)}$ However, while drivers in Ukraine reported similar resolution tendencies for anger provoking situations, in that adaptive/constructive responses were more likely and personal physical expressions of aggression were the least likely, their scores on the factors were higher than those from drivers in the British Isles. Table 3 shows the comparison in factor means between drivers in Ukraine and drivers from the British Isles. Drivers in Ukraine reported higher levels of both the adaptive methods of dealing with anger and the more aggressive forms of anger expression, like using the vehicle to express anger and personal physical aggressive expression. Therefore, although the tendency to resolve the situation with less aggressive actions was similar across the two groups, drivers in Ukraine reported higher levels of most of the aggressive expressions of anger.

\section{[insert Table 3 about here]}

\subsection{Factor structure of the DAX_revised}

The factor structure of the 25-item DAX was tested through Confirmatory Factor Analysis (CFA) using EQS for windows (version 6.1). As the output showed that Mardia's normalised estimate was greater than 5.00, suggesting non-normally distributed data, the robust method of maximum likelihood (ML) was utilised.

The goodness-of-fit indices applied to confirm factor fit were the Santorra-Bentler Scales ChiSquared (S-B $\left.\chi^{2}\right), \mathrm{S}-\mathrm{B} \chi^{2} / d f$, adjusted Comparative Fit Index (CFI) and the Root Mean Square Error of Approximation (RMSEA). Permissible model fit was indicated by an $\mathrm{S}-\mathrm{B} \chi^{2} / d f<5$; adjusted CFI of 0.90 or greater (see ${ }^{45,46}$ ) and an RMSEA no higher than $0.08 .{ }^{(47)}$ The $90 \%$ confidence interval (CI) surrounding the RMSEA was also examined. 
The initial CFA showed poor fit to the data $\left(\mathrm{S}-\mathrm{B} \chi^{2}(269)=1002.21, \mathrm{p}<.001, \mathrm{~S}-\mathrm{B} \chi^{2 /} \mathrm{df}=3.72\right.$, $\mathrm{CFI}=.74, \mathrm{RMSEA}=.08 ; 90 \% \mathrm{CI}=.08-.09)$. Lagrange Multiplier Tests revealed eleven error-pairs to be covaried. As can be seen in Figure 1, it made conceptual sense to co-vary each of these error-pairs. Eight of these were from the adaptive/constructive factor, two from the personal physical factor and one from the verbal aggressive expression factor. Two of these sets of error pairs were also co-varied in the British Isles sample. ${ }^{(24)}$ These were Items 26: "Think of positive solutions to deal with the situation" and Item 35 "Think of positive things to do" and Item 5 "Call the other driver names aloud" and Item 6 "Make negative comments about the driver aloud". This highlights some consistency between the two samples of drivers. Modification indices also showed item 27 "I do to other drivers what they did to me" had a stronger loading on to the personal physical factor than the use of a vehicle factor. Therefore, this item was dropped from the final model (see Figure 1).

The final model had 65 free parameters and showed good fit to the data $\left(\mathrm{S}-\mathrm{B} \chi^{2}(235)=\right.$ $\left.510.39, \mathrm{p}<.001, \mathrm{~S}-\mathrm{B} \chi^{2 /} \mathrm{df}=2.17, \mathrm{CFI}=.90, \mathrm{RMSEA}=.06 ; 90 \% \mathrm{CI}=.05-.06\right)$.

\section{[insert Figure 1 about here]}

Overall the model had acceptable internal consistency $($ Rho $=.72)$ and within method convergent validity was also demonstrated by statistically significant regression coefficients and $92 \%$ of the loadings being $>0.40$. Figure 1 and Table 2 show the composite reliability (Figure 1) and Cronbach's alpha (Table 2) scores for the four factors. As can be seen in both, adaptive/constructive behaviours, personal physical aggressive expression and verbal aggressive forms of anger expression demonstrated good consistency, with both Cronbach's alpha and composite reliability scores being > .70. However, the Cronbach's alpha and composite reliability for use of the vehicle to express anger was lower than ideal $(\alpha \& \omega=$ $.62)$, although Bagozzi and $\mathrm{Yi}^{\left({ }^{(4)}\right)}$ suggest that acceptable composite reliability values for a CFA are those over 0.60, indicating this is still acceptable.

Figure 1 shows the factor loadings and error pairs in the model. As can be seen in Figure 1, Item 7: "Follow right behind for a long time" had a low loading on the use of the vehicle factor. Item 31: "Swear at the other driver under my breath" also had a low loading on the verbal aggressive expression factor, perhaps suggesting these items are not representative of aggressive responses to anger in this sample of drivers from Ukraine. 


\subsection{Intercorrelations among variables}

Table 4 shows that the DAX factors shared moderate correlations ( $r \mathrm{~s}-.33-.50)$, indicating that they were related but separate constructs. As was found in Stephens and Sullman, ${ }^{(24)}$ verbal aggressive expression scores were strongly related to the total aggressive expression score, suggesting that a large proportion of the variance in the total aggressive expression score is from this factor. The measure of driving anger, DAS_short was moderately related to trait anger scores, again showing that they were related but separate constructs. Scores for both of these were moderately, positively related to verbal aggressive expression and use of the vehicle to express anger, but negatively related to Adaptive/Constructive means of dealing with anger. Sex was unrelated to anger propensity scores as well as anger expression scores.

\section{[insert Table 4 about here]}

\subsection{DAX by sex and gender roles}

To understand the contribution of gender role on aggressive forms of anger expression, multiple regression analyses were conducted on the parametric variables for adaptive/constructive expression, verbal aggressive expression and use of vehicle to express anger.

Stepwise regression analyses were conducted with age and gender added at Step 1, trait anger and trait driving anger added at Step 2 and scores for masculine and feminine gender roles added at Step 3 (see Table 5). The results showed that trait anger and driving trait anger reliably predicted higher levels of aggressive forms of anger expression and lower tendencies for these predicted more adaptive constructive forms of managing driving anger. Sex was not found to be a significant predictor of any of the DAX subscales. However, more endorsement of feminine traits predicted higher levels of adaptive/constructive methods of managing anger, but lower levels of personal physical aggressive expression, verbal aggressive expression and total aggressive expression.

The endorsement of feminine traits made the largest contribution to the prediction of the adaptive/constructive form of anger expression. Feminine gender roles, trait anger and trait driving anger accounted for $54 \%$ of the variance in adaptive/constructive scores. Feminine role endorsement contributed $22 \%$ of the variance explained. The contribution was notably less for verbal expressions of anger (1\% of the variance explained), only $6 \%$ for use of a vehicle to express anger and $2 \%$ for personal physical expressions of anger. These findings 
suggest that the endorsement of feminine traits, rather than sex, is a protective factor against aggressive forms of driving anger expression.

\section{[insert Table 5 about here]}

\subsection{DAX by crashes}

Mann Whitney U tests were conducted to compare scores on Adaptive / Constructive means of dealing with anger, verbal aggressive expression, use of vehicle to express anger and total aggressive expression between drivers who, during the last three months, had or had not: received a traffic ticket (excluding parking tickets); lost concentration while driving; lost control of the vehicle; experienced a near-miss; had a crash (major \& minor combined).

Very few differences emerged between DAX scores when these were compared between drivers who reported crash-related behaviours with those who did not $(p \mathrm{~s}>.05)$. The exceptions were that drivers who had recently received a traffic infringement notice $(N=39)$ had significantly higher scores for the three aggressive forms of anger expression, such as verbal aggressive expression $(M=2.17, S D=.93)$, use of the vehicle to express anger $(M=$ $1.90, S D=.55)$, personal physical aggressive expression $(M=1.41, S D=.67)$ and consequently total aggressive expression $(M=1.82, S D=.56)$. The means and z scores for those who had not recently received a traffic ticket $(N=346)$ were: verbal aggressive expression: $M=1.93, S D=.57 ; z=-2.50, p<.05, r=.13$; use of vehicle: $M=1.55, S D=.47 ; z$ $=-2.85, p<.01, r=.15$; personal physical aggressive expression: $M=1.23, S D=.44 ; z=-$ 1.97, $p<.05, r=.10$; and total aggressive expression $M=1.57, S D=.39 ; z=-3.15, p<.01, r=$ .16. Scores for verbal aggressive expressions of anger were also higher for drivers who reported having a near miss $(N=83 ; M=2.15, S D=.64)$, than those who did not $(N=302 ; M$ $=1.92, S D=.56 ; z=-2.06, p<.05, r=.10)$ and also for drivers who reported more losses of concentration $(N=157 ; M=2.05, S D=.60)$, compared to those who did not $(N=221 ; M=$ $1.89, S D=.56 ; z=-2.38, p<.05, r=.12$ ). Therefore, drivers who engage in more verbal aggressive expressions of anger seem more likely to be those engaging in crash-related behaviours.

\section{Discussion}

The present research validated a refined, shorter version of the Driving Anger Expression Inventory (DAX). Confirmatory Factor Analysis supported the original factor structure of the 25-item version of the DAX. ${ }^{(24)}$ However, some modifications were required to achieve satisfactory fit, including the omission of one item. These four factors were also the same as 
the original DAX ${ }^{(26)}$ and that found by other research using the 49 -item version. ${ }^{(25,28)}$ Furthermore, the Personal Physical Aggressive Expression factor was the weakest of the four, which is in keeping with the two studies which did not find support for this factor. ${ }^{(23,27)}$ This may be related to age, as the randomly selected national sample included in Sullman's (23) research had a much higher average age ( $M=49$ years old), than all other studies which supported this factor, such as Stephens and Sullman $(M=38),{ }^{(24)}$ Sullman et al. $(M=26),{ }^{(28)}$ Herrero-Fernandes $(\operatorname{mdn}=22)^{(31)}$ and Deffenbacher et al. $(\operatorname{mdn}=19) .{ }^{(26)}$ The only study which appears to disagree with this hypothesis is the French research, which had a mean age of 22 years old. (27) However, it is likely that other unmeasured variables might be responsible, such as socio-economic status or a combination of measured and unmeasured variables.

Compared with research from the British Isles, ${ }^{(24)}$ the subscales means reported by the Ukrainian drivers were significantly higher for all factors except Verbal Aggressive Expression. A medium effect size was observed for the comparison for Use of Vehicle to express anger, while the other significant difference showed small effect sizes. Therefore, it appears that drivers from Ukraine are just as likely to use Verbal Aggressive expression as those from the UK and Ireland, while they are more likely to use the other two aggressive forms, particularly Use of the Vehicle and also adaptive/constructive expression. The finding that Ukrainian drivers reported engaging more often in both aggressive and non-aggressive methods of dealing with their anger may appear paradoxical. However, angrier individuals have more opportunities to deal with their anger in both a functional and a dysfunctional manner. Related to this, a second possible explanation could be that individuals who engage more often in aggressive expression may also have a greater need to attempt to control and reduce their anger and aggressive expression, also leading to elevated adaptive/constructive expression. In support of those explanations, the trait driving anger scores from the Ukrainian drivers were also reliably higher than those from the British Isles, suggesting that drivers in the Ukraine may be angrier. Nevertheless, as found amongst drivers in Malaysia, ${ }^{(28)} \mathrm{New}$ Zealand , ${ }^{(23)}$ France, ${ }^{(27)}$ USA ${ }^{(26)}$ and Turkey ${ }^{(25)}$ the most common method of dealing with anger while driving for Ukrainian drivers was through adaptive/constructive measures and a medium effect size was observed for this difference. Individually the most frequently reported of these behaviours was to pay closer attention to other's driving to avoid crashes.

The present study also tested the convergent and discriminant validity of the shortened DAX. Convergent validity was supported due to the relationships the resultant factors had with general trait anger and trait driving anger, which is in-line with previous research (e.g., ${ }^{18,23 \text {, }}$ 
${ }^{27}$ ). Discriminant validity was also supported by the relationships the factors had with the crash-related conditions. For example, all three forms of aggressive anger expression (and total aggressive expression) were higher for drivers who had recently received a traffic ticket. However, only small effect sizes were observed for these comparisons. Verbal Aggressive Expression was also related to loss of concentration and near misses, which supports the findings of previous research (e.g., ${ }^{24,25}$ ). However, unlike Sullman ${ }^{(23)}$ there were no relationships found between the DAX factors and crashes. This is due to the small number of crashes reported in the present study $(n=28)$. Although the Driving Survey uses a period of three months, given the rarity of crashes it would be more appropriate to measure crashes over a longer time period in future research.

The present study found sex was not significantly related to the expression of driving anger. This finding supports several previous studies (e.g., ${ }^{24,33}$ ), but also contrasts with several studies which reported higher aggressive expression amongst males (e.g., ${ }^{18,26,32}$ )and higher adaptive/constructive expression among females (e.g., ${ }^{30,32}$ ). Although Stephens and Sullman (24) put these inconsistent findings down to differences in driving populations, sampling techniques or the slightly different factor structures used, it may actually be due to the fact that these studies measured sex rather than gender role.

In the present study, it was gender role, rather than sex, which was related to the expression of driving anger. Those reporting higher levels of femininity reported less aggressive expression of driving anger. Surprisingly, drivers endorsing masculine gender roles were no more likely to report aggressive responses to anger. This contradicts previous findings which have linked masculinity with more aggressive driving. ${ }^{(49)}$ However, Mast et al. ${ }^{(49)}$ only included male drivers and did not measure masculine or feminine traits. It may be that in a mixed sample of drivers the effect of masculinity is reduced. Further, the link between gender roles and aggression might be linked to perceived social roles, which are less clear in the driving context. In support of the present findings, these researchers suggest that sex does not influence the likelihood of aggression, but it is the gender role adopted by the driver that is important. This is a unique finding and supports previous research hypotheses that gender roles create a social boundary that determines which behaviours are "appropriate" for that individual.

The intercorrelations between the DAX factors were all moderate, demonstrating similar patterns to those from other countries using the longer scale. ${ }^{(18,24,26,31)}$ The moderate nature of these relationships indicates that these factors are related but measure separate components 
of anger expression, as found in previous research (e.g., ${ }^{24,}{ }^{31}$ ).Also in line with previous research, age was positively correlated with Verbal Aggressive Expression, ${ }^{(25)}$ but in contrast to previous research, age was not significantly related to Use of a Vehicle to express anger or Total Aggressive Expression. ${ }^{(25,29,30)}$ Also surprisingly age was not related to trait driving anger and had a low, but significant, correlation with general trait anger. These are unusual findings for age, which normally demonstrates consistent findings across studies and countries. Perhaps the inconsistent finding here is due to cultural differences or the slightly smaller sample size in the present study.

\subsection{Limitations}

As this study relied on self-reported data, it is possible that social desirability bias may have influenced the results. It is also likely that self-selection bias may have influenced the findings of this research. It is difficult to estimate the degree to which both forms of bias may have affected the results in a country which differs considerably, both politically and historically, from the Western countries in which most research has been conducted. Research from Western countries suggests that if the participants' names were not recorded and they were assured of total confidentiality and anonymity, the impact of social desirability bias is not likely to be significant (e.g., ${ }^{50,51}$ ), but Ukraine is not a Western country. Furthermore, as Ukraine is classified as a "middle income" country with an underdeveloped infrastructure ${ }^{(52)}$ it is likely that a substantial proportion of the population did not have internet access and were thus unable to take part in the survey. Unfortunately the present study did not have the resources to fund an alternative method of data collection. Given the above, it is possible that this group of Ukrainian drivers are not representative of Ukrainian drivers in general. Another potential limitation of this study was the low number of female participants and the uneven proportions in the four BSRI groups. Therefore, future research amongst Ukrainian drivers should collect data in a more inclusive manner, including drivers without internet access as well as a higher proportion of females.

\subsection{Summary and Practical implications}

The 25-item DAX was found to have good internal reliability, as well as good discriminant and convergent validity. Furthermore, the integrity of the structure proposed by Deffenbacher et al. ${ }^{(26)}$ was retained in the shorter version of the DAX, resulting in four-factors related to anger expression (Adaptive/Constructive, Verbal Aggressive, Use of the Vehicle and Personal Physical Aggressive Expression). The shortened version of the DAX takes less time to complete, is easier to use in conjunction with other scales and will not require such a large 
sample size to undertake the appropriate analyses. Therefore, future research should explore the modified version of the scale in a more representative sample of Ukrainian drivers.

This study supports previous research that has shown positive relationships between the aggressive forms of anger expression and crash-related conditions, such as traffic tickets and near misses. Further, the present study has demonstrated relationships between self-reported aggressive tendencies and gender-roles. This found that femininity was related to less aggressive expression of anger. Finally, these findings were made in Ukraine, a country with an extremely high road fatality rate which is in need of further attention from road safety experts.

In summary, the present study supported the original four factors of the DAX using the revised 25-item scale in a novel sample of Ukrainian drivers. This research also supported the convergent and discriminant validity of the scale and found gender roles to be more important than biological sex in the terms of the expression of driving anger.

\section{References}

1. Global Status Report on Road Safety 2013: supporting a decade of action. Geneva, Switzerland: World Health Organisation (WHO).WHO, 2013. pp. vii, 1-8, 53ff (countries), 244-251 (table A2), 296-303 (table A10). ISBN 9789241564564. Retrieved 2014-05-30.

2. Deffenbacher JL, Deffenbacher DM, Lynch RS, Richards TL. Anger, aggression, and risky behavior: a comparison of high and low anger drivers. Behaviour Research and Therapy, 2003; 41(6): 701-718.

3. Ellison-Potter P, Bell P, Deffenbacher JL. The effects of trait driving anger, anonymity, and aggressive stimuli on aggressive driving behavior. Journal of Applied Social Psychology, 2001; 31(2):431-443.

4. Goehring JB. Aggressive driving: Background and overview report. National Conference of State Legislatures,2000.(Retrieved July 21,2001, from the World Wide Web: http://www.ncsl.org/programs/esnr/aggrdriv.htm)

5. Neighbors C, Vietor NA, Knee CR. A motivational model of driving anger and aggression. Personality and Social Psychology Bulletin, 2002; 28(3):324-335.

6. Pickford BW. Experiences of aggressive behavior and its effect regarding road rage. University of Michigan-Flint, 2004.

7. Smart RG, Mann RE. Is road rage a serious traffic problem? Traffic Injury Prevention, 2002b; 3(3): 183-189. 
8. Sullman MJ. Anger amongst New Zealand drivers. Transportation Research Part F: Traffic Psychology and Behaviour, 2006; 9:173-184.

9. Stephens AN, Groeger JA. Anger-congruent behaviour transfers across driving situations. Cognition \& Emotion, 2011; 25(8): 1423-1438.

10. Stephens AN, Trawley SL, Madigan R, Groeger JA. Drivers display anger congruent attention to potential traffic hazards. Applied Cognitive Psychology, 2013; 27(2):178189.

11. Stephens AN, Groeger JA. Following slower drivers: Lead driver status moderates driver's anger and behavioural responses and exonerates culpability.Transportation Research Part F: Traffic Psychology and Behaviour, 2014; 22:140-149.

12. Garrity RD, Demick J. Relations among Personality Traits, Mood States, and Driving Behaviors. Journal of Adult Development, 2001; 8(2):109-118.

13. Lansdown TC, Stephens AN, Couples, contentious conversations, mobile telephone use and driving. Accident Analysis \& Prevention, 2013; 50: 416-422.

14. Abdu R, Shinar D, Meiran N.Situational (state) anger and driving. Transportation Research Part F: Traffic Psychology and Behaviour, 2012; 15: 575-580.

15. Mesken J, Hagenzieker MP, Rothengatter T, de Waard D. Frequency, determinants, and consequences of different drivers' emotions: An on-the-road study using selfreports, (observed) behaviour, and physiology. Transportation Research Part F: Traffic Psychology and Behaviour, 2007; 10(6):458-475.

16. Stephens AN, Groeger JA. Situational specificity of trait influences on drivers' evaluations and driving behaviour. Transportation Research Part F: Traffic Psychology and Behaviour, 2009; 12(1):29-39.

17. Smart RG, Mann RE.Deaths and injuries from road rage: cases in Canadian newspapers. Canadian Medical Association Journal, 2002a; 167(7):761-762.

18. Dahlen ER, Regan KM. Validation of the Propensity for Angry Driving Scale. Journal of Safety Research, 2004; 35(5):557-563.

19. Underwood G, Chapman P, Wright S, Crundall D. Anger while driving. Transportation Research Part F: Traffic Psychology and Behaviour, 1999; 2(1):55-68.

20. Deffenbacher JL, Oetting ER, Lynch RS.Development of a driving anger scale. Perceptual and motor skills,1994;74(1):83-91.

21. Deffenbacher JL, Lynch RS, Filetti LB, Dahlen ER,Oetting ER. Anger, aggression, risky behaviour, and crash-related outcomes in three groups of drivers. Behaviour Research and Therapy, 2003; 41(3): 333-349.

22. Deffenbacher JL. Anger, aggression, and risky behavior on the road: A preliminary 
study of urban and rural differences. Journal of Applied Social Psychology, 2008; 38(1):22-36.

23. Sullman MJ. The expression of anger on the road. Safety Science, 2015; 72:153-159.

24. Stephens AN, Sullman MJ. Development of a short form of the driving anger expression inventory. Accident Analysis \& Prevention, 2014;72: 169-176.

25. Sullman MJ, Stephens AN, Kuzu D. The expression of anger amongst Turkish taxi drivers. Accident Analysis \& Prevention,2013;56:42-50.

26. Deffenbacher, JL, Lynch, RS, Oetting, ER, Swaim, RC. The driving anger expression inventory: A measure of how people express their anger on the road. Behaviour Research and Therapy, 2002; 40(6): 717-737.

27. Villeux A, Delhomme P. Driving anger and its expressions: Further evidence of validity and reliability for the Driving Anger Expression Inventory French adaptation. Journal of Safety Research, 2010; 41(5):417-422.

28. Sullman MJ, Stephens AN, Yong M. Anger, Aggression and road rage behaviour in Malaysian drivers. Transportation Research Part F: Traffic Psychology and Behaviour, $2015 ; 29: 70-82$.

29. Sarbescu P. Aggressive driving in Romania: Psychometric properties of the driving anger expression inventory. Transportation Research Part F: Traffic Psychology and Behaviour, 2012; 15(5):556-564.

30. Jovanovic D, Lipovac K, Stanojevic P, Stanojevic D. The effects of personality traits on driving-related anger and aggression behaviour in traffic among Serbian drivers. Transportation Research Part F: Traffic Psychology ad Behaviour, 2011;14(1):43-53.

31. Herrero-Fernandez D. Psychometric adaptation of the Driving Anger Expression Inventory in a Spanish sample: Differeces by age and gender. Transportation Research Part F: Traffic Psychology and Behaviour, 2011; 14(4):324-329.

32. Esiyok B, Yasak Y, Korkusuz I. Anger expression on the road: validity and reliability of the driving anger expression inventory. Turk Psikiyatri Derg, 2007; 18(3):231-243.

33. Björkqvist K. Sex differences in physical, verbal, and indirect aggression: A review of recent research. Sex Roles, 1994; 30(3-4):177-188.

34. Stephens AN, Sullman MJ. A comparison of anger, aggression and crash related behaviors across drivers from the United Kingdom and Irish Republic. Risk Analysis, 2015; 35(9):1730-1745.

35. Ozkan T, Lajunen T. Why are there sex differences in risky driving? The relationship between sex and gender - role on aggressive driving, traffic offences, and accident involvement among young Turkish drivers. Aggressive Behavior, 2005; 31(6):547- 
558.

36. Bem SL. Bem sex-role inventory: Professional manual. Palo Alto, CA: Consulting Psychologists Press, 1981.

37. Rowland R. The bem sex-role inventory. Australian Psychologist, 1977; 12(1):83-88.

38. Deffenbacher JL, Kemper CC, Richards TL. The driving anger expression inventory: A validity study with community college student drivers. J. Psychopathol. Behavior. Assess, 2007; 29(4): 220-230.

39. Moore M, Dahlen ER. Forgiveness and consideration of future consequences in aggressive driving. Accident Analysis \& Prevention, 2008; 40 (5):1661-1666.

40. Spielberger C.D. State-Trait Anger Expression Inventory ( $1^{\text {st }}$ ed.). Odessa, FL: Psychological Assessment Resources, 1988.

41. Sullman MJ, Stephens AN.A comparison of the driving anger scale and the propensity for angry driving scale. Accident Analysis \& Prevention, 2013; 58: 88-96.

42. Spielberger C.D. State-Trait Anger Expression Inventory ( $2^{\text {nd }}$ ed.). Odessa, FL: Psychological Assessment Resources. 1999.

43. Colley A, Mulhern G, Maltby J, Wood A. The short form BSRI: Instrumentality, expressiveness and gender associations among a United Kingdom sample. Personality and Individual Differences, 2009; 46(3):384-387.

44. Cohen J. A power primer. Psychological bulletin, 1992; 112(1):155-159.

45. Bollen K.A.Structural equations with latent variables. New York: Wiley, 1989.

46. Raykov T, Marcoulides GA. A first course in structural equation modeling. Lawrence Erlbaum Associates: London, 2006.

47. MacCallum RC, Browne MW, Sugawara HM. Power analysis and determination of sample size for covariance structure modeling. Psychological methods, 1996; 1(2):130-149.

48. Bagozzi RP, Yi Y. On the evaluation of structural equation models. Journal of the Academy of Marketing Science, 1988; 16(1):74-94.

49. Mast MS, Sieverding M, Esslen M, Graber K, Jäncke L. Masculinity causes speeding in young men. Accident Analysis \& Prevention, 2008; 40(2):840-842.

50. Lajunen T, Summala H. Can we trust self-reports of driving? Effects of impression management on driver behaviour questionnaire responses. Transportation Research Part F: Traffic Psychology and Behaviour, 2003; 6(2):97-107.

51. Sullman MJ, Taylor JE. Social desirability and self-reported driving behaviours: Should we be worried? Transportation Research Part F: Traffic Psychology and Behaviour, 2010; 13(3):215-221. 
52. What are Middle-Income Countries? World Bank, 2014. Retrieved 4 November 2014 from:http://go.worldbank.org/BDZHSEY4J0 
Table 1: Age, licence history and preferred speed by sex

\begin{tabular}{|c|c|c|c|c|}
\hline Variable & Males $(N=245)$ & Females $(N=140)$ & $t(383)$ & $\begin{array}{l}\text { Cohen's } \\
d\end{array}$ \\
\hline & Average $(S D)$ & Average $(S D)$ & & \\
\hline Annual kilometres travelled & $8,711(6,124)$ & $10,864(10,046)$ & $-2.27 *$ & .32 \\
\hline Mean age (years) & $33.28(8.79)$ & $34.54(10.37)$ & -1.21 & .15 \\
\hline Length of licence (years) & $9.68(9.07)$ & $8.44(9.62)$ & 1.23 & .15 \\
\hline Preferred speed on motorway $(130 \mathrm{~km} / \mathrm{h})$ & $129.07(24.41)$ & $121.40(20.92)$ & $3.12 * *$ & .32 \\
\hline Preferred speed on busy main street $(50 \mathrm{~km} / \mathrm{h})$ & $58.98(16.61)$ & $56.85(15.83)$ & 1.23 & .13 \\
\hline Preferred speed in residential areas $(60 \mathrm{~km} / \mathrm{h})$ & $76.51(16.91)$ & $69.95(12.48)$ & $4.01 * * *$ & .41 \\
\hline Preferred speed in pedestrian zones $(20 \mathrm{~km} / \mathrm{h})$ & $25.23(12.78)$ & $25.76(11.64)$ & $<1$ & .04 \\
\hline Preferred speed on regional roads $(100 \mathrm{~km} / \mathrm{h})$ & $108.78(19.89)$ & $100.39(17.95)$ & $4.13^{* * *}$ & .42 \\
\hline
\end{tabular}


Table 2: Item and factor means for the DAX revised (25 item scale)

\begin{tabular}{lll}
\hline DAX items & $\mathrm{N}=385$ \\
& $\mathrm{M}(S D)$ \\
\hline Adaptive/Constructive Expression from DAX 25-items $(\alpha=.87)$ & $2.67(.65)$ \\
\hline 49 & Pay closer attention to other's driving to avoid accidents & $3.02(.91)$ \\
30 & Not stoop to their level & $2.89(1.01)$ \\
23 & Pay closer attention to being a safe driver & $2.86(.97)$ \\
26 & Think of positive solutions to deal with the situation & $2.85(.95)$ \\
42 & Accept there are bad drivers on the road & $2.73(.99)$ \\
45 & Accept there are frustrating situations & $2.66(.96)$ \\
35 & Think of positive things to do & $2.50(.93)$ \\
48 & Tell myself to ignore it & $2.46(.95)$ \\
36 & Tell myself it's not worth getting involved & $2.40(.91)$ \\
29 & Tell myself it's not worth getting mad at & $2.31(.95)$ \\
\hline Verbal Aggressive Expression $(\alpha=.74)$ & $1.96(.59)$ \\
\hline 6 & Make negative comments about the driver aloud & $2.26(.69)$ \\
31 & Swear at the other driver under my breath & $2.22(.96)$ \\
28 & Swear at the other driver aloud & $2.03(.90)$ \\
5 & Call the other driver names aloud & $1.75(.80)$ \\
38 & Yell at the other driver & $1.53(.81)$ \\
\hline Use of Vehicle to Express Anger $(\alpha=.68)$ & $1.64(.49)$ \\
\hline
\end{tabular}




\begin{tabular}{lll}
\hline 27 & Drive a lot faster & $1.90(.77)$ \\
7 & Follow right behind for a long time & $1.72(.76)$ \\
22 & Do to drivers what they did to me & $1.57(.74)$ \\
2 & Drive right up on the other driver's bumper & $1.56(.69)$ \\
15 & Speed up to frustrate other driver & $1.46(.77)$ \\
\hline Personal Physical Aggressive Expression $(\alpha=.86)$ & $1.25(.47)$ \\
\hline 10 & Roll down the window to communicate my anger & $1.38(.66)$ \\
21 & Try to scare the driver & $1.29(.61)$ \\
8 & Try to get out of the car and tell the other driver off & $1.23(.58)$ \\
17 & Bump the driver's bumper with my own & $1.18(.58)$ \\
41 & Try to get out and have a physical fight & $1.16(.45)$ \\
\hline Total Aggressive Expression (no Adaptive items)( $\alpha=.84)$ & $1.62(.41)$
\end{tabular}


Table 3: Comparison of factor means for the DAX revised (25 item) for data from drivers in Ukraine and the British Isles

\begin{tabular}{|c|c|c|c|c|c|}
\hline & $\begin{array}{l}\text { Number } \\
\text { of items }\end{array}$ & $\begin{array}{l}\text { Ukraine } \\
N=385 \\
M(S D)\end{array}$ & $\begin{array}{l}\text { British } \\
\text { Isles }^{\#} \\
N=550 \\
M(S D)\end{array}$ & $t(933)=$ & Cohen's $d$ \\
\hline $\begin{array}{l}\text { Adaptive/Constructive } \\
\text { Expression }\end{array}$ & 10 & $2.67(.65)$ & $2.30(.58)$ & $9.13 * * *$ & .60 \\
\hline Verbal Aggressive Expression & 5 & $1.96(.59)$ & $2.02(.58)$ & 1.54 & .10 \\
\hline $\begin{array}{l}\text { Use of Vehicle to Express } \\
\text { Anger }\end{array}$ & 5 & $1.64(.49)$ & $1.33(.40)$ & $10.62 * * *$ & .70 \\
\hline $\begin{array}{l}\text { Personal Physical Aggressive } \\
\text { Expression }\end{array}$ & 5 & $1.25(.47)$ & $1.16(.37)$ & $3.27 * * *$ & .21 \\
\hline Total aggressive expression & 15 & $1.62(.41)$ & $1.50(.37)$ & $4.67 * * *$ & .31 \\
\hline
\end{tabular}
$\#(34) ; * * * p<.001$ 
Table 4: Intercorrelations between variables $(N=385)$

$\begin{array}{llllllllll}1 & 2 & 3 & 4 & 5 & 6 & 7 & 8 & 9 & 10\end{array}$

1. Age

2. $\operatorname{Sex}^{\#}$

.06

3. Years licensed $.68^{* * *}$

$-.06$

4. Annual mileage $.18 * * *$

$.13 *$

.03 
5. TAS

$$
-.13 * *
$$$$
-.13 *
$$$$
-.08
$$

6. DAS_short

$-.08$

$-.07$

$.04 \quad-.05$

$25 * * *$

7. $\mathrm{A} / \mathrm{C}$

.09

.01

.10

.06

$-.15^{* *}$

$-.14 * *$

8. VAE

$-.11 *$

$-.06$

$-.0$

.03

$.37 * * *$

$.35^{* * *}$

9. $\mathrm{UoV}^{\bullet}$
$-.09$

.01

$-.08$

$.13^{*}$

$.32 * * *$
$.43 * * *$ 


\begin{tabular}{|c|c|c|c|c|c|c|c|c|c|c|}
\hline 10. PPAE & -.02 & -.05 & -.03 & -.03 & $.23 * *$ & .09 & $-.32 * * *$ & $.34 * * *$ & $.50 * * *$ & --- \\
\hline $11 T A E^{\star}$ & -06 & -.05 & -.04 & -.01 & $.41 * * *$ & $.33 * * *$ & $-.38 * * *$ & $.84 * * *$ & $.77 * * *$ & $.66 * * *$ \\
\hline \multirow{2}{*}{ Means (SD) } & \multirow{2}{*}{$\begin{array}{l}33.74 \\
(9.41)\end{array}$} & & & & $2.07(.56)$ & $2.85(.66)$ & $1.97(.49)$ & $1.59(.51)$ & $1.25(.45)$ & $1.60(.51)$ \\
\hline & & & & & $\alpha=.80$ & $\alpha=.81$ & & & & \\
\hline
\end{tabular}

"Sex: 1=males, 2=females; A/C = Adaptive Constructive; PPAE = Personal Physical; VAE = Verbal; UoV = Use of Vehicle; DAS = driving anger scale; the means for each scale were used (not the sum of items)

Italic: Spearman's Rho, all others Pearson correlations *** $p \leq .001 ; * * p \leq .01 ; * p \leq .05$;

${ }^{\star}$ with item 27 removed from the UoV factor 
Table 5: Anger expression by gender-role

\begin{tabular}{|c|c|c|c|c|}
\hline Model & Variable & $B$ & $R^{2}$ & $\Delta R^{2}$ \\
\hline \multicolumn{5}{|l|}{ Adaptive / Constructive } \\
\hline Step 1 & Age & .07 & .03 & $.03 *$ \\
\hline \multirow[t]{2}{*}{$F(3,384)=3.64, p<.05$} & TAS & $-.14 * *$ & & \\
\hline & Gender & .01 & & \\
\hline Step 2 & Age & .08 & .05 & $.02 * *$ \\
\hline \multirow[t]{3}{*}{$F(4,384)=4.60, p<.01$} & TAS & $-.13^{*}$ & & \\
\hline & Gender & -.02 & & \\
\hline & Feminine & $.14 * *$ & & \\
\hline Step 3 & Age & .08 & .06 & $.01 *$ \\
\hline \multirow[t]{4}{*}{$F(5,384)=4.83, p<.001$} & TAS & -.09 & & \\
\hline & Gender & -.02 & & \\
\hline & Feminine & $.16^{* *}$ & & \\
\hline & DAS & $-.12 *$ & & \\
\hline \multicolumn{5}{|l|}{ Verbal Expressions of anger } \\
\hline Step 1 & Age & -.06 & .14 & $.14^{* * *}$ \\
\hline \multirow[t]{2}{*}{$F(4,384)=20.91, p<.001$} & TAS & $.36^{* * *}$ & & \\
\hline & Gender & -.07 & & \\
\hline
\end{tabular}




\begin{tabular}{|c|c|c|c|c|}
\hline Step 2 & Age & -.05 & .21 & $.07 * * *$ \\
\hline \multirow[t]{3}{*}{$F(4,384)=24.87, p<.001$} & TAS & $.29 * * *$ & & \\
\hline & Gender & -.05 & & \\
\hline & DAS & $.27 * * *$ & & \\
\hline Step 3 & Age & -.05 & .22 & $.01 *$ \\
\hline \multirow[t]{4}{*}{$F(4,384)=21.36, p<.001$} & TAS & $.27 * * *$ & & \\
\hline & Gender & -.03 & & \\
\hline & DAS & $.29 * * *$ & & \\
\hline & Feminine & $-.11^{*}$ & & \\
\hline \multicolumn{5}{|l|}{ Use of Vehicle to express } \\
\hline anger & Age & -.05 & .12 & $.12 * * *$ \\
\hline Step 1 & TAS & $.33 * * *$ & & \\
\hline$F(3,384)=16.45, p<.001$ & Gender & .01 & & \\
\hline Step 2 & Age & -.04 & .17 & $.06^{* * *}$ \\
\hline \multirow[t]{3}{*}{$F(4,384)=19.37, p<.001$} & TAS & $.27 * * *$ & & \\
\hline & Gender & .02 & & \\
\hline & DAS & $.24 * * *$ & & \\
\hline \multicolumn{5}{|l|}{ Personal Physical } \\
\hline Expressions of anger & Age & -.03 & .05 & $.05^{* * *}$ \\
\hline Step 1 & TAS & $.22 * * *$ & & \\
\hline$F(3,384)=6.84, p<.001$ & Gender & -.10 & & \\
\hline
\end{tabular}




\begin{tabular}{|c|c|c|c|c|}
\hline Step 2 & Age & -.04 & .07 & $.02 * *$ \\
\hline \multirow[t]{3}{*}{$F(4,384)=7.05, p<.001$} & TAS & $.21 * * *$ & & \\
\hline & Gender & .03 & & \\
\hline & Feminine & $-.14 * *$ & & \\
\hline Step 3 & Age & -.03 & .08 & $.01 *$ \\
\hline \multirow[t]{4}{*}{$F(5,384)=6.56, p<.001$} & TAS & $.18 * * *$ & & \\
\hline & Gender & .04 & & \\
\hline & Feminine & $-.15^{* *}$ & & \\
\hline & DAS & $.11^{*}$ & & \\
\hline \multicolumn{5}{|l|}{ Total Aggressive Expression } \\
\hline Step 1 & Age & -.06 & .16 & $.16^{* * *}$ \\
\hline \multirow[t]{2}{*}{$F(3,384)=24.26, p<.001$} & TAS & $.39 * * *$ & & \\
\hline & Gender & -.03 & & \\
\hline \multicolumn{5}{|l|}{ Step 2} \\
\hline \multirow[t]{3}{*}{$F(4,384)=26.98, p<.001$} & Age & -.05 & .22 & $.06^{* * *}$ \\
\hline & TAS & $.32 * * *$ & & \\
\hline & Gender & -.01 & & \\
\hline
\end{tabular}



DAS
$.26 * * *$

\begin{tabular}{|c|c|c|c|c|}
\hline Step 3 & Age & -.06 & .24 & $.02 * * *$ \\
\hline \multirow[t]{4}{*}{$F(5,384)=24.33, p<.001$} & TAS & $.30 * * *$ & & \\
\hline & Gender & .01 & & \\
\hline & DAS & $.28 * * *$ & & \\
\hline & Feminine & $-.15 * * *$ & & \\
\hline
\end{tabular}

$* * * p \leq .001 ; * * p \leq .01 * \mathrm{p} \leq .05 ;$ DAS $=$ Driving Anger Scale; TAS = Trait Anger Scale 


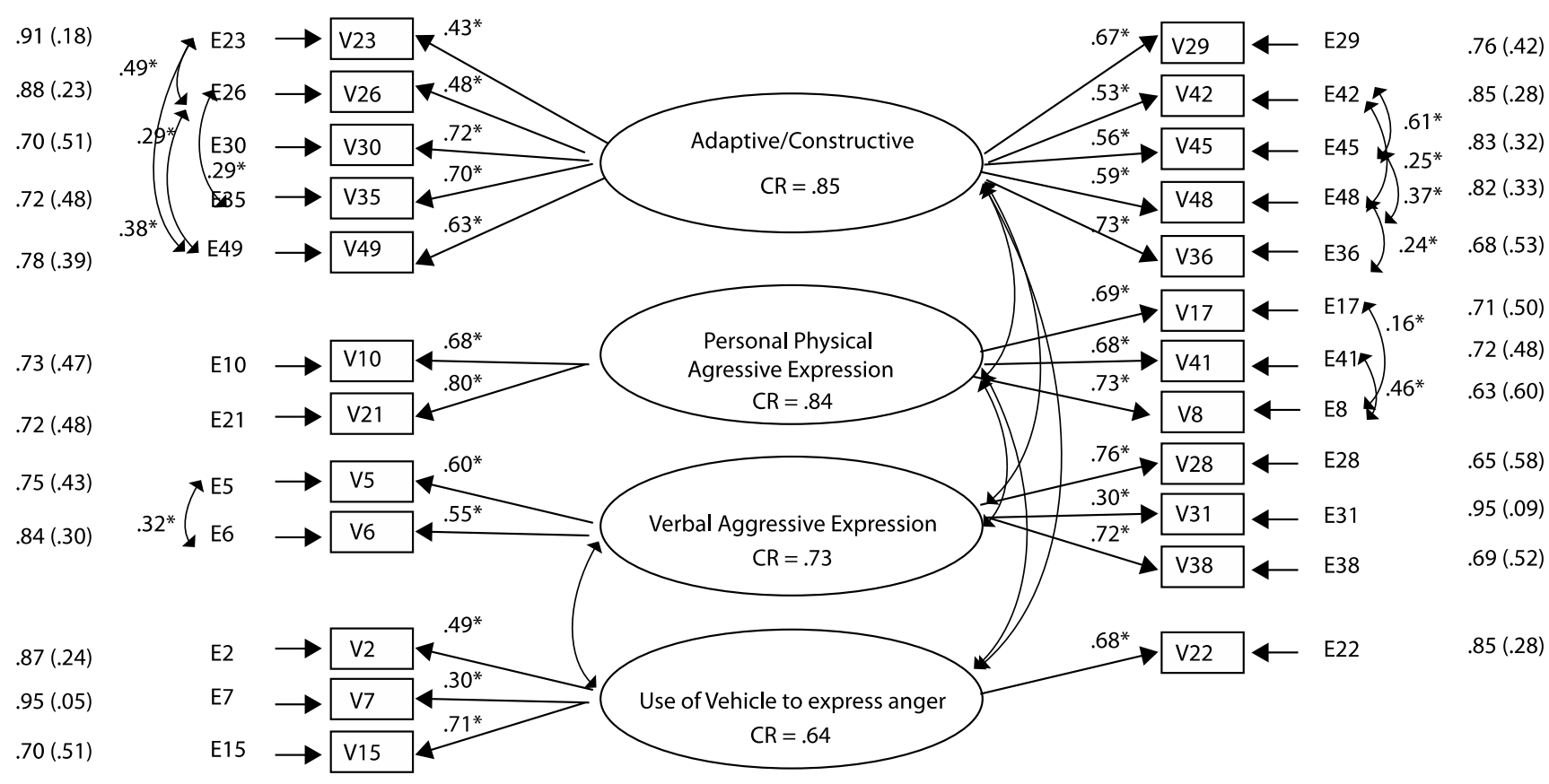

Figure 1: Confirmatory Factor Analysis of DAX_25 items with standardised error (r-square in brackets) 
2016-03-10

\section{Gender roles and the expression of driving anger among Ukrainian drivers}

Sullman, Mark J. M.

Wiley: 24 months

Sullman MJ, Stephens AN, Hill T, Gender roles and the expression of driving anger among Ukrainian drivers, Risk Analysis, Volume 37, Issue 1, January 2017, Pages 52 - 64.

http://dx.doi.org/10.1111/risa.12592

Downloaded from Cranfield Library Services E-Repository 